\title{
Regulation of basal metabolic rate in uncomplicated pregnancy and in gestational diabetes mellitus
}

\author{
Eleftheria Taousani, ${ }^{1,2}$ Dimitra Savvaki, ${ }^{1}$ Efrosini Tsirou, ${ }^{1}$ Pavlos Poulakos, ${ }^{1}$ \\ Gesthimani Mintziori, ${ }^{1}$ Menelaos Zafrakas, ${ }^{2}$ Basil C. Tarlatzis, ${ }^{1}$ \\ Dimitrios Vavilis, ${ }^{1}$ Dimitrios G. Goulis ${ }^{1}$ \\ ${ }^{1}$ Unit of Reproductive Endocrinology, First Department of Obstetrics and Gynecology, Medical School, Aristotle University \\ of Thessaloniki, Thessaloniki, Greece; ${ }^{2}$ Department of Midwifery, Alexander Technological Educational Institute of \\ Thessaloniki, Sindos, Greece
}

\begin{abstract}
Basal metabolic rate (BMR) is one of the major components of total energy expenditure (TEE). It is affected by various factors, such as body weight, body composition, age, race/ethnicity, gender, biochemical parameters, physical activity, and health status. Gestational diabetes mellitus (GDM) is the most common metabolic disorder during pregnancy and it increases the risk for health complications, such as stillbirth, diabetes mellitus, and cardiovascular disease in later life. Both BMR and GDM have been linked with gestational weight gain (GWG), a fact suggesting a possible association between them. However, assessing BMR is a complex procedure, which becomes more complicated when additional parameters, such as pregnancy and GDM, are taken into consideration. The present review summarizes the current knowledge on factors affecting BMR and its regulation in relation to pregnancy and GDM. Future research addressing these associations should thoroughly consider other factors that affect BMI when designing such studies and/or discussing the BMR outcome results.
\end{abstract}

Key words: Affecting factors, Basal metabolic rate, Energy expenditure, Gestational diabetes mellitus, Pregnancy

\section{INTRODUCTION}

The measurement of basal metabolic rate (BMR) is

\section{Address for correspondence:}

Eleftheria Taousani, Unit of Reproductive Endocrinology, First Department of Obstetrics and Gynecology, Aristotle University of Thessaloniki, "Papageorgiou" General Hospital, Ring Road, 56403, Nea Efkarpia, Thessaloniki, Greece;

Tel.: +30 2310233468 ,

E-mail: tausani@midw.teithe.gr, liataou@yahoo.gr

Received: 03-05-2017, Accepted: 24-09-2017 widely used for the assessment of metabolic activity in various groups and conditions. Gestational diabetes mellitus (GDM) is the most common metabolic disorder during pregnancy. ${ }^{1}$ Both BMR and GDM have been associated with the same factors, ${ }^{2,3}$ suggesting a link between BMR and GDM (Table 1). The most indicative factor seems to be gestational weight gain (GWG). GDM is increasing worldwide in parallel with overweight and obesity ${ }^{4}$ and several recent studies have identified GWG as an important 
Table 1. Regulating factors of BMR and GDM

\begin{tabular}{|c|c|c|c|c|c|}
\hline Factor & Specific Factor & $\begin{array}{c}\text { Effect on } \\
\text { BMR }\end{array}$ & $\begin{array}{c}\text { Reference } \\
\text { studies }\end{array}$ & $\begin{array}{c}\text { Effect on } \\
\text { GDM }\end{array}$ & $\begin{array}{c}\text { Reference } \\
\text { studies }\end{array}$ \\
\hline Age & Age & $\downarrow$ & 24,26 & $\uparrow$ & 128,130 \\
\hline \multirow[t]{20}{*}{ Biomarkers } & \multirow[t]{2}{*}{ Triiodothyronine $\left(\mathrm{T}_{3}\right)$} & $\uparrow$ & $10,56,57$ & $\downarrow$ & 173 \\
\hline & & - & 22,58 & & \\
\hline & \multirow[t]{2}{*}{ Thyroxine $\left(\mathrm{T}_{4}\right)$} & $\uparrow^{\mathrm{M}}$ & 15 & $\downarrow$ & 172,173 \\
\hline & & $\downarrow$ & 57 & & \\
\hline & \multirow[t]{2}{*}{ Cortisol } & $\downarrow$ & 11 & - & 152,168 \\
\hline & & & & $\uparrow^{1}$ & 171 \\
\hline & \multirow[t]{2}{*}{ Adiponectin } & $\downarrow^{2}$ & 62 & $\downarrow^{3}$ & $162-164$ \\
\hline & & -4 & 64 & - & 165 \\
\hline & \multirow[t]{2}{*}{ Leptin } & - & 15,60 & - & 165,167 \\
\hline & & -2 & 61 & $\uparrow^{3}$ & 164,166 \\
\hline & \multirow[t]{2}{*}{ Insulin } & $\uparrow$ & 66 & $\uparrow$ & 154,155 \\
\hline & & & & - & 153 \\
\hline & Insulin-like Growth Factor-1 (IGF-1) & $\uparrow$ & 10,67 & $\downarrow$ & 169,170 \\
\hline & Fasting plasma glucose (FPG) & $\downarrow^{5}$ & 68 & $\uparrow$ & 152,153 \\
\hline & Sex hormone binding globulin (SHBG) & \multicolumn{2}{|c|}{ No studies found } & $\downarrow$ & 158,159 \\
\hline & Iron deficiency (serum ferritin and total body iron) & \multicolumn{2}{|c|}{ No studies found } & $\downarrow$ & 174 \\
\hline & \multirow[t]{2}{*}{ C-reactive protein } & $\uparrow$ & 69,70 & $\uparrow$ & 158,168 \\
\hline & & - & 71 & & \\
\hline & Tumor necrosis factor alpha (TNF- $\alpha)$ & -6 & 23 & $\uparrow$ & 161,162 \\
\hline & Adipocyte fatty acid-binding protein (AFABP) & No stu & s found & $\uparrow$ & 162 \\
\hline \multirow[t]{3}{*}{ Body composition } & Fat-free mass & $\uparrow$ & $10,15,21$ & $\downarrow$ & 142 \\
\hline & Fat mass & $\uparrow$ & $10,15,21$ & $\uparrow$ & 142 \\
\hline & Body composition* & $\downarrow^{2}$ & 23 & $\uparrow$ & $141,142,143$ \\
\hline \multirow[t]{6}{*}{ Body weight } & Gestational body weight & $\uparrow$ & $9,10,11$ & $\uparrow$ & 142 \\
\hline & \multirow[t]{3}{*}{ Gestational weight gain (GWG) } & $\uparrow$ & 12 & $\uparrow$ & $1,107,141$ \\
\hline & & & & $\uparrow-7$ & 109 \\
\hline & & - & 20 & - & 108 \\
\hline & Pregestational body weight & $\downarrow$ & 10 & $\uparrow$ & 120 \\
\hline & Weight gain $^{R}$ & $\downarrow$ & 17 & $\uparrow$ & 141 \\
\hline Medication & Sympathomimetic medication & $\uparrow^{2}$ & 90 & $\uparrow$ & 151 \\
\hline \multirow[t]{2}{*}{ Nutrition } & \multirow[t]{2}{*}{ Caffeine } & $\uparrow^{2}$ & 87 & & \\
\hline & & & & -8 & 154 \\
\hline
\end{tabular}


Table 1. (continued) Regulating factors of BMR and GDM

\begin{tabular}{|c|c|c|c|c|c|}
\hline Factor & Specific Factor & $\begin{array}{c}\text { Effect on } \\
\text { BMR }\end{array}$ & $\begin{array}{l}\text { Reference } \\
\text { studies }\end{array}$ & $\begin{array}{c}\text { Effect on } \\
\text { GDM }\end{array}$ & $\begin{array}{l}\text { Reference } \\
\text { studies }\end{array}$ \\
\hline \multirow[t]{4}{*}{ Physical activity } & Endurance exercise training in normal altitude & - & 78,79 & \multicolumn{2}{|c|}{ No studies found } \\
\hline & Endurance exercise training in high altitude & $\uparrow$ & 80 & \multicolumn{2}{|c|}{ No studies found } \\
\hline & Physically active women with increased BMI & \multicolumn{2}{|c|}{ No studies found } & $\downarrow$ & 1 \\
\hline & Higher levels of physical activity & $\uparrow^{2}$ & 82 & $\downarrow$ & 146,147 \\
\hline \multirow[t]{3}{*}{ Psychological factors } & Stressful events & \multicolumn{2}{|c|}{ No studies found } & $\uparrow$ & 148 \\
\hline & Bipolar disorder & \multicolumn{2}{|c|}{ No studies found } & - & 149 \\
\hline & Current major depressive disorder & \multicolumn{2}{|c|}{ No studies found } & - & 149 \\
\hline \multirow[t]{3}{*}{ Race/Ethnicity } & African-American & $\downarrow$ & $37-40$ & $\uparrow$ & 134 \\
\hline & Sub-Saharan Africans & $\downarrow$ & 36 & $\uparrow^{9}$ & 133 \\
\hline & Caucasian & $\uparrow$ & 35 & $\downarrow^{10}$ & 129 \\
\hline \multirow[t]{3}{*}{ Sleep restriction } & \multirow[t]{3}{*}{ Sleep restriction } & $\downarrow$ & 44 & \multirow[t]{3}{*}{$\uparrow^{12}$} & \multirow[t]{3}{*}{150} \\
\hline & & $\downarrow^{11}$ & 87 & & \\
\hline & & - & 88 & & \\
\hline Socio-economic status & Lower socioeconomic status & $\downarrow$ & 91,92 & $\uparrow$ & 129 \\
\hline $\begin{array}{l}\text { Type } 2 \text { diabetes } \\
\text { Mellitus (T2DM) }\end{array}$ & $\begin{array}{l}\text { T2DM in various ethnicities, after adjustment } \\
\text { for FM and FFM age and sex }\end{array}$ & $\uparrow$ & $83,84,85$ & $\uparrow^{R}$ & 125,127 \\
\hline
\end{tabular}

Positive $(\uparrow)$, negative $(\downarrow)$ or lack of correlation (-) of each factor with either BMR or GDM. The inverse relationship (the effect of BMR or GDM on the factor) is marked with ${ }^{\mathrm{R}}$ and the lack of studies describing the association is indicated by "No studies found". BMI: body mass index; BMR: basal metabolic rate; FFM: free fatty mass; FM: fat mass; GDM: gestational diabetes mellitus.

${ }^{\mathrm{M}}$ : in men, but not in women; *: referring to a higher pregestational BMI; ${ }^{\mathrm{P}}$ : reverse relationship; ${ }^{1}$ : after daily cortisol infusion in ewes; 2: effect on/associated with RMR, not BMR; ${ }^{3}$ : in early pregnancy; ${ }^{4}$ : correlation with energy expenditure, not BMR; ${ }^{5}$ : in mice; ${ }^{6}$ : in obese women; ${ }^{7}$ : $\uparrow$ in the first and $\downarrow$ in the second trimester; ${ }^{8}$ : a non-significant negative effect was reported; ${ }^{9}$ : slightly elevated risk compared with non-Hispanic white women; ${ }^{10}$ : in direct association dictated by lower insulin resistance; ${ }^{11}$ : statistically non-significant; ${ }^{12}$ : not significant though after controlling for age and BMI.

and independent risk factor for GDM..$^{5-7}$ Given that weight gain is principally regulated by the imbalance between energy intake and total energy expenditure (TEE) and BMR is a major component of TEE, BMR has also been associated with GWG. ${ }^{8-12}$

Several studies state that a low prepregnancy BMR is associated with increased GWG, which increases the risk for GDM (Figure 1a). ${ }^{13}$ Others claim that excessive GWG, in part due to increased maternal circulatory, respiratory and renal functions, is associated with increased risk for GDM. ${ }^{3}$ In this case, the higher BMR observed appears to be a mere epiphenomenon of the increased GWG (Figure 1b). (a)

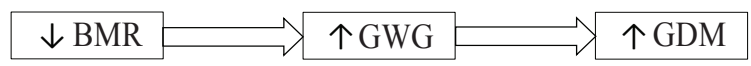

(b)

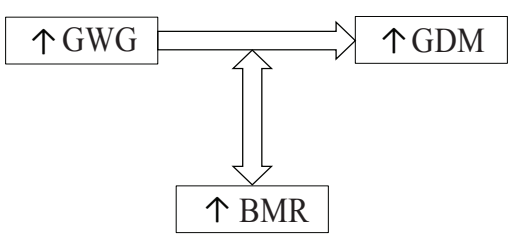

Figure 1. Hypotheses regarding the association between BMR and GDM: (a) Decreased prepregnancy BMR as a causative factor of GDM development, (b) Increased BMR as an epiphenomenon in GDM development. BMR: basal metabolic rate; GDM: gestational diabetes mellitus; GWG: gestational weight gain. 
Although several studies have examined the relationship between BMR and GWG during normal pregnancy, to date there is no study describing this relationship in women with GDM. Therefore, the present review aims to present and critically appraise the current knowledge about the factors affecting BMR in normal pregnancy and in women with GDM in order to identify possible associations and suggest directions for future research.

\section{BASAL METABOLIC RATE}

BMR, defined as "the rate of energy expenditure (EE) in the post-absorptive state after 12-h overnight fast", represents the minimum energy required to maintain all the vital activities and functions in the awake state. ${ }^{2}$ BMR is one of the three principal constituents of TEE, along with the thermic effect of food (TEF) and the EE of activity (activity thermogenesis),${ }^{14}$ and is affected by such factors as age, gender, body composition, race/ethnicity, physical activity, nutrition, hormones, such as leptin, and health status. ${ }^{2}$ This section provides an overview of BMR measurement and describes the most significant factors affecting BMR.

\section{Measurement of BMR}

As BMR is affected by various factors, a significant variation occurs among individuals. ${ }^{15,16}$ Therefore, the measurement of BMR requires specific conditions to be met in order that accurate comparisons may be made. These standardized conditions include the time of the day (preferably between 06:00 and 09:00 h) and the environment (preferably thermoneutral at $22-26^{\circ} \mathrm{C}$ ). Furthermore, the subjects should have slept at the site of the measurement overnight, have fasted for at least 10-12 $\mathrm{h}$ before measurement and be completely rested, awake, motionless, free from emotional stress, and in the supine position. ${ }^{2,14}$ The full description of complete methodology for BMR measurement is beyond the purpose of this paper.

As a principal component of TEE, BMR is used in various research projects. Nevertheless, due to practical issues, resting metabolic rate (RMR) is often used instead. ${ }^{2}$ The experimental conditions for BMR and RMR are similar; however, RMR is measured after at least $4 \mathrm{~h}$ fasting and factors, such as time of the day and physical activity, are not controlled. ${ }^{2}$ RMR is about $10 \%$ to $20 \%$ higher than BMR. ${ }^{2}$ Therefore, scientists need to take this difference into account when comparing RMR with BMR.

\section{Body weight and composition}

RMR and BMR have been proposed by some, ${ }^{17-19}$ but not all, ${ }^{20}$ researchers to be independent factors of weight gain, after adjustment for fat-free mass (FFM), fat mass (FM), age, and sex. Conversely, FFM is well-established as the principal predictor of BMR, ${ }^{10,15,21}$ while the contribution of FM to BMR seems more complex. FM is also positively associated with BMR, ${ }^{10,15,21}$ but this association appears to be exponential and dependent on the relation between FM and body weight. ${ }^{21}$ After weight loss, FFM and FM account for almost $50 \%$ of the Resting Energy Expenditure (REE) decrease. ${ }^{22}$ Furthermore, body mass index (BMI) is negatively associated with RMR/ $\mathrm{kg}$ and, thus, BMR. ${ }^{23} \mathrm{In}$ addition, both RMR $/ \mathrm{kg}$ of body weight or RMR/kg FFM decrease with weight gain due to the decline of the relative contributions of the most metabolically active organs, such as the brain, liver, and heart. ${ }^{2}$ However, individual variation exists and other factors should also be evaluated. The associations of BMR with body weight parameters in pregnancy are discussed in sections 3.1 and 3.2.

\section{Age}

TEE declines approximately 10 and $7 \mathrm{kcal} /$ year for men and women, respectively, ${ }^{2}$ and BMR, as a significant component of TEE, declines by $1-2 \%$ per decade. ${ }^{24}$ However, the increased heterogeneity of the elder groups compared with the younger makes BMR prediction difficult. ${ }^{25}$ Although BMR in general declines, ${ }^{26}$ some subjects show in fact an increase with ageing. ${ }^{25}$ BMR reduction with age is partly explained by the loss of FFM and the gain of FM. ${ }^{26,27}$ FFM seems to account for most of the BMR variability (about $60 \%$ ), but it is not the only factor involved. ${ }^{27,28} \mathrm{BMR}$ is lower in older compared to younger adults, even when adjusted for FFM, with the reduction ranging across the studies from 4.6 to over $13 \% .{ }^{29,30}$ In addition, the reduction in RMR due to age is greater than what can be attributed to FM or FFM. ${ }^{31}$ Recent evidence on REE indicates that BMR decline is also affected by decreases in: a) the 
contribution in organ and muscle masses to FFM and b) specific organ and tissue metabolic rates. ${ }^{32}$

\section{Race and ethnicity}

A number of studies report ethnicity as a factor affecting BMR levels, ${ }^{2}$ although factors such as methodology, ${ }^{33}$ physical activity, and nutrition ${ }^{34}$ might influence the reported ethnic differences. Caucasians seem to have higher BMR levels than non-Caucasians, ${ }^{35}$ while sub-Saharan Africans have been reported to have lower RMR levels. ${ }^{36}$ African-American adults ${ }^{37-40}$ and children ${ }^{41-44}$ have lower basal or resting energy expenditure levels, and thus BMR levels, than their white counterparts. However, this appears unlikely to account for weight gain in this population. ${ }^{45}$ Furthermore, African-American healthy adults seem to have a lower RMR than Caucasian independently of sleep duration. ${ }^{46}$ Moreover, a decline in REE, proportional to the amount of lost fat and lean mass, was reported for white but not for black women. ${ }^{47}$ Racial differences in BMR levels are also detected between indigenous and non-indigenous circumpolar groups, variations that are attributed to different thyroid responses to environmental stressors. ${ }^{48}$ Furthermore, total daily energy expenditure (TDEE) seems to be explained by variation in physical activity energy expenditure rather than REE in women ${ }^{49}$ or RMR in children. ${ }^{50}$ Gannon et al raise methodological concerns about the measurement of RMR with indirect calorimetry, the measurement of body composition and the menstrual cycle variation in RMR in studies examining RMR in African-Americans versus Caucasians. ${ }^{33}$ Further research, with particular focus on the experimental design and BMR affecting factors, would shed light on the detected racial RMR and BMR variance.

\section{Gender}

Gender differences in BMR levels are mostly attributable to differences in body composition and hormones. ${ }^{2}$ After adjustment for body composition, male adolescents seem to have higher BMR levels and energy expenditure than females, ${ }^{51-53}$ although not all researchers agree. ${ }^{54}$ However, even though obese male children and adolescents appear to have increased BMR levels compared to females, this difference was not detected in obese adults. ${ }^{27}$ In addition, it has been suggested that BMR variance depends on the menstrual cycle, with the follicular phase being
$6-15 \%$ lower than the luteal phase. ${ }^{2}$ However, there are other studies that report no effect of the menstrual cycle on BMR. ${ }^{55}$ Despite this discrepancy, it is strongly recommended to record the menstrual cycle phase in studies examining BMR in women.

\section{Biomarkers}

Thyroid hormones have been linked to BMR variation, but the literature is limited on this subject and presents contradicting reports. BMR and both triiodothyronine $\left(T_{3}\right)$ and the free $T_{3}$ index seem to be positively associated after adjustment for body composition, ${ }^{56,57}$ but not all the studies agree. ${ }^{15,58}$ By contrast, thyroxine $\left(\mathrm{T}_{4}\right)$ was both positively ${ }^{15}$ and negatively ${ }^{59}$ associated with BMR. Furthermore, $\mathrm{T}_{4}$ appears to have an effect on BMR levels in men, but not in women. ${ }^{15}$ Clearly, the effects of $\mathrm{T}_{4}$ on BMR require further investigation.

Leptin, adiponectin and resistin are members of the adipokine family. Leptin is linked with FM and body weight, but does not appear to be directly associated with BMR levels. ${ }^{15,60,61}$ The association of serum adiponectin with BMR is in dispute, as studies have found contradictory results describing a negative, ${ }^{62}$ a positive ${ }^{63}$ or no association. ${ }^{64}$ Circulating resistin has been connected with markers of obesity, insulin resistance and inflammation. ${ }^{65}$ However, we are not aware of any studies examining the association between resistin and BMR in humans.

Other hormones and cytokines, such as cortisol, fasting insulin, insulin-like growth factor 1 (IGF1), C-reactive protein (CRP), and tumor necrosis factor-alpha (TNF- $\alpha$ ), have been examined for their association with BMR. Despite the findings of a negative association between maternal cortisol levels and $\mathrm{BMR}$, increases in maternal cortisol concentration levels were reported to determine $27.1 \%$ of the BMR variation during pregnancy, ${ }^{11}$ indicating a possible role of cortisol in GWG and a potential association with GDM. Furthermore, fasting insulin levels ${ }^{66,67}$ and IGF- $1^{10,67}$ have been positively associated with RMR or BMR, while the levels of fasting glucose seem to have a negative association with BMR. ${ }^{68}$ In contrast, the association between CRP and BMR is not yet clear, as the limited studies report conflicting findings. ${ }^{69-71}$ Finally, there is no apparent direct association between TNF- $\alpha$ and BMR. ${ }^{23}$ 


\section{Physical activity}

Physical activity is one of the most important components of TEE. Physical activity level (PAL), defined as the ratio of TEE / BEE, is "commonly used to describe typical physical activity levels". ${ }^{2}$ However, the PAL approach used to calculate physical activity level has certain limitations and might produce errors in the estimation of both TEE and activity energy expenditure (AEE).$^{72}$ The effects of physical activity on BMR are controversial and depend on specific parameters of physical activity, such as age, exercise volume,${ }^{73}$ intensity, duration, frequency and type of exercise. ${ }^{74}$ Cross-sectional studies comparing endurance athletes with untrained control subjects report contradictory results with either no significant differences ${ }^{75,76}$ or an association pointing to higher levels in athletes. ${ }^{77}$ Longitudinal studies on physical activity effects exerted on BMR are also controversial. Endurance exercise training does not seem to affect RMR levels at normal altitudes ${ }^{78,79}$ but appears to affect it when performed at high altitudes ${ }^{80}$ Although a 12 -week endurance training program failed to induce changes in RMR, it prevented the decrease of RMR that was found in the non-training control group. ${ }^{81}$ Furthermore, physically active women seem to have a higher RMR than sedentary women. ${ }^{82}$

\section{Diabetes}

Type 2 diabetes mellitus (T2DM) has been positively associated with higher BMR levels in Pima Indians ${ }^{83}$ Caucasians,${ }^{84}$ and Japanese ${ }^{85}$ Higher BMR levels in obese individuals with T2DM range from 5.2-7.1\%, after adjustment for FFM, FM, age, and sex. ${ }^{84,85}$ In addition, a number of parameters have been identified as determinants of RMR in patients with T2DM: basal endogenous glucose output (3-3Hglucose), fasting insulin and free-fatty acid (FFA) concentrations, and glucose disposal. ${ }^{66}$ The association of BMR levels with GDM is discussed in section 5.

\section{Other parameters}

Several additional factors have been associated with BMR levels. Sleep restriction seems to decrease RMR levels, ${ }^{46,86}$ albeit not all studies are in agreement about this ${ }^{87}$ Sympathomimetic medications have also been reported to increase RMR, ${ }^{88}$ while drugs, such as amphetamines, ephedrine, and some antidepressants, could increase BMR. In contrast, drugs, including propranolol, reserpine, and bethanidine, may reduce it. ${ }^{2}$ Although smoking seems to reduce $24-\mathrm{h} \mathrm{EE},{ }^{89}$ the effect of cigarette smoking on BMR remains unclear. ${ }^{2}$ Lower socioeconomic status appears to be associated with lower BMR levels. ${ }^{90,91}$

\section{PREGNANCY}

Pregnancy requires an additional amount of energy due to increased basal metabolism (BMR), the energy cost of physical activity and energy deposition for the development of maternal and fetal tissues, ${ }^{2}$ as well as for the woman's gradual increase in cardiac output and respiratory rate. ${ }^{92}$ In addition, pregnancy is characterized by increased GWG due to higher demands for synthesis and maintenance of maternal tissue along with elevated fat deposition in order to support mother and fetus. ${ }^{93-95}$ Several factors have been proposed as being associated with BMR variation during pregnancy, including GWG, prepregnancy body fatness, IGF-1, thyroid hormones, and fetal size. ${ }^{10}$ This section briefly describes the factors of pregnancy that are linked or possibly associated with BMR and/or GDM. The association between BMR and GDM is described in section 5.

\section{Normal pregnancy and BMR}

BMR and its association with various factors in healthy and diabetic individuals were described in section 2. The relation of BMR with pregnancy is briefly described here.

A number of studies report increased BMR or RMR levels throughout pregnancy. ${ }^{3}$ The increases in BMR range from 124 to $157 \mathrm{MJ}$ for the entire pregnancy ${ }^{93}$ or from 8 to $35 \% .{ }^{3}$ During late pregnancy, the fetus contribution to the BMR increase is about $50 \%{ }^{2}$ However, wide variability has been reported. ${ }^{10,93}$ Several factors have been implicated in the variability of BMR in pregnancy, including prepregnancy body weight and body fatness, lean body weight, ${ }^{96}$ reduced daily activity during pregnancy, ${ }^{95}$ changes in serum concentration of metabolism related-hormones, ${ }^{68}$ diabetes ${ }^{96}$ and cardiac output changes.${ }^{10}$ Nonetheless, controversy exists in regard to the magnitude of the contribution of each factor.

\section{Gestational weight gain}

The amount of GWG is critical, since it can have 
short- and long-term effects on both infant and maternal health. ${ }^{97}$ Within the recommended range, GWG is associated with improved birth outcome for both mother and fetus in regard to birth weight and perinatal complications. ${ }^{98}$ On the other hand, excessive GWG is independently associated with adverse maternal and neonatal outcomes, such as pre-eclampsia, cesarean delivery, perineal laceration, postpartum hemorrhage, macrosomia, large for gestational age (LGA) neonates, and neonatal intensive care unit (NICU) admission. ${ }^{99,100}$ Several lines of evidence support the association between excessive weight gain during pregnancy with increased birthweight, ${ }^{101-103}$ independently of genetic factors. ${ }^{102}$ Siega-Riz et al report an association between inadequate GWG and decreased birthweight. ${ }^{101}$ Furthermore, GWG is associated with postpartum body fat and weight retention ${ }^{104}$ and it has been identified as an independent risk factor for GDM, ${ }^{1,105,106}$ even though not all studies agree. ${ }^{107} \mathrm{GWG}$ during the first trimester of pregnancy, but not during the second, was identified as an independent risk factor for GDM. ${ }^{99,108}$ Moreover, Morisset et al report that every $\mathrm{kg}$ of weight gain during the first trimester of pregnancy increased the risk for GDM by $25 \% .{ }^{99}$

\section{Physical activity in pregnancy}

The controversial effects of physical activity in BMR levels are described in section 2.7. During pregnancy, physical activities require additional EE. ${ }^{2}$ Weight-bearing activities increase EE by about $19 \%$ after 25 weeks of gestation, while non-weight-bearing activities increase it by about $10 \% .{ }^{94}$ Despite the additional energy required, possible reductions in PAL would counterbalance the effect of increased BMR levels and, thus, variation in TEE levels would remain low. Although the physical and mental benefits of exercise have been reported, ${ }^{109}$ physical activity effects on total EE of pregnant women are controversial due to variation of PAL and methodological issues. ${ }^{95}$ Most of the studies examining physical activity during pregnancy use methods of limited validity and reliability, questionnaires or interviews, which might inaccurately estimate physical activity levels. ${ }^{95} \mathrm{In}$ addition, the majority of the studies examining the relation between recreational physical activity and two important pregnancy outcomes, birthweight and length of gestation, do not assess significant physical activity variables such as type, frequency, intensity, and duration. ${ }^{110}$

\section{Nutrition}

Nutrition is crucial to energy balance and thus to weight control. As described in section "Gestational weight gain", insufficient or excessive GWG may lead to various negative outcomes. Nutritional interventions could reduce excessive GWG and improve outcomes for both mother and baby. ${ }^{111}$ Energy demands increase with pregnancy by $300 \mathrm{kcal} /$ day on average, but there is variation between trimesters and among women. ${ }^{112}$ However, recommendations for a $240 \mathrm{kcal} /$ day increase may support excessive weight gain and its negative outcomes. ${ }^{113}$ The requirements for the majority of nutrients also increase with pregnancy: proteins (by $25 \mathrm{~g} / \mathrm{d}$ ), iron, vitamins A, C, B group, as well as fiber and various minerals. In contrast, the recommendations for fluoride, calcium, and vitamins D, E, and $\mathrm{K}$ do not increase with pregnancy. ${ }^{112}$ Tanentsapf et al report lack of sufficient evidence to support the hypothesis that nutrition interventions could reduce the incidence of pre-eclampsia, macrosomia, and GDM. ${ }^{114}$ Nevertheless, more recent studies reveal associations between nutritional interventions and congenital anomalies, pre-eclampsia, ${ }^{115}$ and $\mathrm{GDM}^{116,117}$ and indicate the potential benefits of nutrition-specific and nutrition-sensitive interventions.

\section{Pregnancy outcomes in pre-existing diabetes}

Excess pregestational weight is significantly associated with cesarean delivery, gestational hypertension/ pre-eclampsia, and GDM. ${ }^{118}$ Furthermore, women with pre-existing diabetes mellitus have higher risks for negative pregnancy outcomes than women with GDM. ${ }^{119}$ Women with pre-existing diabetes also have an increased rate of cesarean delivery than women with GDM, ${ }^{120,121}$ indicating a possible higher rate of macrosomia. This indication has been confirmed by the study of Wahabi et al in which the authors identified associations of pre-existing diabetes with increased risk for macrosomia, stillbirth, preterm delivery, and low APGAR scores at 5 min. ${ }^{121}$

\section{GESTATIONAL DIABETES MELLITUS}

GDM is the most common metabolic disorder during pregnancy. ${ }^{1}$ It is defined as "carbohydrate 
intolerance of varying degrees of severity with onset or first recognition during pregnancy". ${ }^{122}$ The global prevalence of GDM rates ranges from 3 to $14 \% .{ }^{123}$ GDM is associated with several health complications for both the mother and the infant, including metabolic and respiratory complications, cesarian section, ${ }^{124}$ cardiovascular disease, and development of T2DM for the mother ${ }^{125,126}$ and macrosomia (birth weight above $4 \mathrm{~kg}$ ), low birth weight $(<2.5 \mathrm{~kg})$, and stillbirth for the infant. ${ }^{124,127}$

There are several non-modifiable and modifiable factors associated with GDM. Age, ethnicity, parity, and socioeconomic status are non-modifiable factors that affect the risk for GDM. ${ }^{128-130}$ Advanced maternal age is related to hypertension and GDM. ${ }^{131}$ The risk of GDM increases significantly and progressively from $2.1 \%$ in women aged below 25 years old to $7.0 \%$ in women aged 35 years or more. ${ }^{132}$ Moreover, the GMD recurrence rate is about $48 \%$, with primiparous and Caucasian women having lower recurrence rates than multiparous and other ethnicities, respectively. ${ }^{133}$ The risk for development of GDM varies between different ethnic groups. Among the ethnic groups, Asians seem to have the highest risk for GDM development, followed by Middle Eastern, Caribbean, Central and South American, African-American, sub-Saharan African, Hispanic and Caucasian individuals. ${ }^{134-136}$ Finally, lower socioeconomic status, disadvantaged place of residence, multiple pregnancies, and marriage or partnership status are among the socioeconomic factors that increase the risk for developing GDM. ${ }^{129}$

Modifiable factors include excess prepregnancy weight, ${ }^{118}$ body composition, nutrition, ${ }^{120,137-140}$ physical activity, and excess GWG. ${ }^{99}$ BMI change ${ }^{141}$ and BMI gain between pregnancies ${ }^{142}$ are also important risk factors for GDM for multiparous women. ${ }^{142} \mathrm{~A}$ transition from obesity Class I (BMI 30-34.9 kg/ $\mathrm{m}^{2}$ ) to class III (BMI $\left.>40 \mathrm{~kg} / \mathrm{m}^{2}\right)$ results in a two- to nine-fold increase of the risk for GDM. ${ }^{143}$ However, women with increased BMI but who are physically active during pregnancy have a $50 \%$ reduction in the risk of developing GDM. ${ }^{1}$ Moreover, FM and FFM have been associated with higher and lower risk for GDM development, respectively. ${ }^{141}$ The evidence for the protective effects of exercise on GDM risk is insufficient. ${ }^{144} \mathrm{~A}$ systematic review and meta-analysis by Russo et al identifies only a slight protective ef- fect of physical activity against GDM. ${ }^{145}$ In contrast, Tobias et al report that women who have higher levels of physical activity seem to have significantly lower risk for GDM, while Sanabria-Martínez et al suggest that structured physical activity programs reduce the risk for the development of GDM. ${ }^{146-147}$

In addition to physiological and environmental factors, psychological stress appears to be linked with GDM. Stressful events were suggested as being an independent risk factor for the development of GDM. ${ }^{148}$ Nevertheless, Sit et al failed to discover significant variations in glucose challenge test responses between mothers with bipolar disorder (BD) or with current major depressive disorder and healthy mothers. ${ }^{149}$ Shorter sleep duration does not seem to have a significant effect on the risk for GDM development despite the reported higher fasting glucose levels after sleep restriction. ${ }^{150}$ Beta-adrenergic agents and corticosteroids appear to increase the risk for GDM development. ${ }^{151}$

Finally, a vast number of biomarkers have been examined for association with GDM, including fasting plasma glucose (FPG), insulin, and sex hormone binding globulin (SHBG). In early pregnancy, FPG levels lower than $80 \mathrm{mg} / \mathrm{dl}$ were negatively associated with GDM risk, while a 1.5-fold increase of GDM development risk was detected for every $5 \mathrm{mg} / \mathrm{dl}$ increase. ${ }^{152}$ Fasting plasma insulin, despite the positive association with GDM in the first two trimesters of pregnancy, ${ }^{153,154}$ and higher levels of insulin do not seem to predict GDM in all patients. ${ }^{155,156}$ In contrast, lower concentrations of SHBG before ${ }^{157}$ and during ${ }^{158}$ the first weeks of pregnancy are associated with the risk for developing GDM and appear to be a better GDM predictor than FPG. ${ }^{159}$ Of the various cytokines and inflammatory markers, only adiponectin, leptin, ${ }^{160}$ TNF- $\alpha$ and its ratio with interleukin-10 (TNF- $\alpha$ /IL$10)^{161}$ as well as the adipocyte fatty acid-binding protein (AFABP) seem to be related to the pathophysiology of GDM. ${ }^{162}$ Both TNF- $\alpha$ and AFABP are positively associated with GDM, ${ }^{161,162}$ Adiponectin levels show a negative association with GDM, ${ }^{162-164}$ even though not all studies agree. ${ }^{165}$ In contrast, leptin seems to be positively related and to predict GDM, ${ }^{164,166}$ but not all studies are in agreement. ${ }^{165,167}$ Also, highsensitive C-reactive protein (hs-CRP) appears to predict GDM. ${ }^{158,168}$ 
IGF-1, cortisol, thyroid hormones $\left(\mathrm{T}_{3}, \mathrm{~T}_{4}\right)$, and iron status markers seem to have a possible role in the development of GMD. More specifically, an inverse association between GDM and both free IGF- $1^{169}$ and IGFBP-1 was detected. ${ }^{169,170}$ Higher levels of cortisol have recently been correlated with hyperglycemia in ewes after daily cortisol infusions, ${ }^{171}$ but cortisol levels do not seem to be associated with GDM. ${ }^{152,168}$ Lower free triiodothyronine $\left(\mathrm{T}_{3}\right)$ was suggested as an independent predictor of GDM,,${ }^{172}$ while thyroxine $\left(\mathrm{T}_{4}\right)$ levels appear to decrease significantly in women with GDM, but only after the first trimester of pregnancy. ${ }^{172,173}$ Iron deficiency defined by serum ferritin and total body iron, but not by transferrin receptor, was recently associated with lower risk for GDM. ${ }^{174}$

\section{BMR AND GDM}

BMR and GDM have both been positively associated with body weight ${ }^{8,142}$ and GWG. ${ }^{7,107,141}$ However, a recent study showed no significant BMR variation between women with and without GDM. ${ }^{175}$ Weight gain is primarily regulated by the imbalance between the energy intake and the $\mathrm{TEE}^{8}$ and GWG is positively associated with increased risk for the development of GDM. ${ }^{1,108}$ Increased BMR is one of the major factors affecting elevated TEE and GWG during pregnancy, despite a partial compensation by a decrease in activity EE ${ }^{68,97}$ Although a low prepregnancy BMR has been linked with a higher body weight ${ }^{6-8}$ and a higher $\mathrm{GWG}^{9}$ during pregnancy, the association between a low BMR and weight gain has been questioned as regards a typical Western population. ${ }^{20}$ However, crucial BMR-affecting factors, such as nutritional status and physical activity, were not evaluated in this study. In addition, there are physiological and metabolic differences between a typical Western population and women with GDM mainly caused by the development of maternal and fetal tissues as well as a gradual increase in cardiac output and respiratory rates. ${ }^{2}$ It has been reported that more than $60 \%$ of the variability in metabolic rate was explained by combining fetal weight and maternal weight gain. ${ }^{10}$

In addition to the relationship between prepregnancy BMR and GWG described above, there seems to be an association between GDM and BMR once GDM has been developed. Obesity affects many aspects of maternal metabolism, including insulin resistance and blood glucose metabolism. ${ }^{176}$ T2DM has been positively associated with higher BMR levels in various ethnicities after adjustment for FFM, FM, age, and sex ${ }^{83-85}$ indicating a possible positive relation of BMR with GDM. However, to date no study has focused on the contribution of BMR among the risk factors for GDM development. This is an interesting field of research which requires further investigation.

\section{CONCLUSIONS}

BMR is one of the three principal components of TEE and is used in many research projects. The various factors affecting BMR can however generate inaccurate results and produce false interpretations when they are not appropriately considered. GDM is the most common metabolic disorder during pregnancy that increases the risk of several health complications for both mother and infant, such as metabolic, respiratory, and cardiovascular disease, and stillbirth. Several factors have been linked to GDM, including age, history of glucose intolerance, delivery of a child with macrosomia or LGA, race, overweight or obesity, GWG, lack of physical activity, insufficient or inadequate nutrition, and psychological factors. Most of these factors, especially GWG, also affect BMR, a fact that suggests a possible association of BMR with GDM. Since a) low prepregnancy BMR is negatively associated with GWG (Figure 1a), b) BMR increases during pregnancy in parallel with GWG, and c) GWG has been linked to GDM, we can assume that BMR might be associated with GDM, most likely through the increase of GWG (Figure 1b). This possible association should be taken into account in future GDM prognostic models. To date, there is not sufficient evidence for the relative contribution of BMR in GDM development. Future research could shed light on this association; until then, the factors affecting BMR should be thoroughly considered when the effect of BMR on GDM and GWG is examined.

\section{AUTHOR CONTRIBUTIONS}

E.T. wrote the first draft and edited the manuscript. D.S. (physical activity), E.T. (diet), P.P. (gestational diabetes) and G.M. (Endocrinology) made significant contributions in their areas of expertise. M.Z., D.V., 
B.C.T. and D.G.G. edited and revised the manuscript for important intellectual content.

\section{CONFLICT OF INTERESTS / FINANCIAL DISCLOSURE}

None for all authors.

\section{REFERENCES}

1. Spaight C, Gross J, Horsch A, Puder JJ, 2016 Gestational Diabetes Mellitus. Endocr Dev 31: 163-178.

2. Butte NF, Caballero B 2014 Energy needs: assessment and requirements. In: Ross AC, Caballero B, Cousins RJ, Tucker KL, Ziegler TR (eds) Modern nutrition in health and disease, Lippincott Williams \& Wilkins; Baltimore/Philadelphia; pp, 88-101.

3. Catalano PM, 1999 Pregnancy and lactation in relation to range of acceptable carbohydrate and fat intake. Eur J Clin Nutr 53(Suppl 1): S124-131.

4. Chu SY, Callaghan WM, Kim SY, et al, 2007 Maternal obesity and risk of gestational diabetes mellitus. Diabetes Care 30: 2070-2076.

5. Hedderson MM, Gunderson EP, Ferrara A, 2010 Gestational weight gain and risk of gestational diabetes mellitus. Obstet Gynecol 115: 597-604.

6. Carreno CA, Clifton RG, Hauth, JC, et al, 2012 Excessive early gestational weight gain and risk of gestational diabetes mellitus in nulliparous women. Obstet Gynecol 119: 1227-1233.

7. Liu Z, Ao D, Yang H, Wang Y, 2014 Gestational weight gain and risk of gestational diabetes mellitus among Chinese women. Chin Med J (Engl) 127: 1255-1260.

8. Hall KD, Heymsfield SB, Kemnitz JW, Schoeller DA, Speakman JR, 2012 Energy balance and its components: implications for body weight regulation. Am J Clin Nutr. 95: 989-994.

9. Bronstein MN, Mak RP, King JC, 1996 Unexpected relationship between fat mass and basal metabolic rate in pregnant women. Br J Nutr 75: 659-668.

10. Lof M, Olaouson H, Bostrom K, Sjoberg B, Sohlstrom A, Forsum E, 2005 Changes in basal metabolic rate during pregnancy in relation to changes in body weight and composition, cardiac output, insulin like growth factor I and thyroid hormones and in relation to fetal growth. Am J Clin Nutr 81: 678-685.

11. Damjanovic SS, Stojic RD, Lalic NM, et al, 2009 Relationship between basal metabolic rate and cortisol secretion throughout pregnancy. Endocrine 35: 262-268.

12. Mărginean C, Mărginean CO, Bănesku C, Melit L, Tripon F, Iancu M, 2016 Impact of demographic, genetic, and bioimpedance factors on gestational weight gain and birth weight in a Romanian population. Medicine (Baltimore) 95: e4098.

13. Adane EE, Tooth LR, Mishra GD, 2017 Pre-pregnancy weight change and incidence of gestational diabetes mellitus: A finding from a prospective cohort study. Diabetes Res Clin Pract 124: 72-80.

14. Levine JA, 2005 Measurement of energy expenditure. Public Health Nutr 8: 1123-1132.

15. Johnstone AM, Murison SD, Duncan JS, Rance KA, Speakman JR, 2005 Factors influencing variation in basal metabolic rate include fat-free mass, fat mass, age, and circulating thyroxine but not sex, circulating leptin or triiodothyronine. Am J Clin Nutr 82: 941-948.

16. Adriaens MP, Schoffelen PF, Westerterp KR, 2003 Intra-individual variation of basal metabolic rate and the influence of daily habitual physical activity before testing Br J Nutr 90: 419-423.

17. Ravussin E, Lillioja S, Knowler WC, et al, 1988 Reduced rate of energy expenditure as a risk factor for body-weight gain. N Engl J Med 318: 467-472.

18. Tataranni PA, Harper IT, Snitker S, et al, 2003 Body weight in free-living Pima Indians: effect of energy intake vs expenditure. Int J Obes Relat Metab Disord 27: 1578-1583.

19. Luke A, Durazo-Arvizu R, Cao G, Adeyemo A, Tayo B, Cooper R, 2006 Positive association between resting energy expenditure and weight gain in lean adult population. Am J Clin Nutr 83: 1076-1081.

20. Anthanont P, Jensen MD, 2016 Does metabolic rate predict weight gain? Am J Clin Nutr 104: 959-963.

21. Müller MJ, Bosy-Westphal A, Later W, Haas V, Heller M, 2009 Functional body composition: insights into the regulation of energy metabolism and some clinical applications. Eur J Clin Nutr 63: 1045-1056.

22. Bosy-Westphal A, Kossel E, Goele K, et al, 2009 Contribution of individual organ mass loss to weight lossassociated decline in resting energy expenditure. Am J Clin Nutr 90: 993-1001.

23. Moradi S, Mirzaei K, Abdurahman AA, Keshavarz SA, 2017 Adipokines may mediate the relationship between resting metabolic rates and bone mineral densities in obese women. Osteoporos Int Jan 23 doi: 10.1007/ s00198-017-3914-6. [Epub ahead of print].

24. Keys A, Taylor HL, Grande F, 1973 Basal metabolism and age of adult man. Metabolism 22: 579-587.

25. Henry CJ, 2000 Mechanisms of changes in basal metabolism during ageing. Eur J Clin Nutr 54(Suppl 3): S77-S91.

26. Roberts SB, Dallal GE, 2005 Energy requirements and aging. Public Health Nutr 8: 1028-1036.

27. Lazzer S, Bedogni G, Lafortuna CL, et al, 2010 Relationship between basal metabolic rate, gender, age, and body composition in 8,780 white obese subjects. Obesity (Silver Spring) 18: 71-78.

28. Krems C, Lührmann PM, Strassburg A, Hartmann B, Neuhäuser-Berthold M, 2005 Lower resting metabolic rate in the elderly may not be entirely due to changes in body composition. Eur J Clin Nutr 59: 255-262.

29. Pannemans DL, Westerterp KR, 1995 Energy expen- 
diture. Physical activity and basal metabolic rate of elderly subjects. Br J Nutr 73: 571-581.

30. Klausen B, Toubro S, Astrup A, 1997 Age and sex effects on energy expenditure. Am J Clin Nutr 65: 895-907.

31. St-Onge MP, Gallagher D, 2010 Body composition changes with aging: the cause or the result of alterations in metabolic rate and macronutrient oxidation? Nutrition 26: 152-155.

32. Geisler C, Braun W, Pourhassan M, et al, 2016 Agedependent changes in resting energy expenditure (REE): Insights from detailed body composition analysis in normal and overweight Caucasians. Nutrients 8: pii:E322.

33. Gannon B, DiPietro L, Poehlman ET, 2000 Do African Americans have lower energy expenditure than Caucasians? Int J Obes Relat Metab Disord 24: 4-13.

34. Lovejoy JC, Champagne CM, Smith SR, de Jonge L, Xie H, 2001 Ethnic differences in dietary intakes, physical activity, and energy expenditure in middleaged, premenopausal women: the Healthy Transitions Study. Am J Clin Nutr 74: 90-95.

35. Cole TJ, Henry CJ, 2005 The Oxford Brookes basal metabolic rate database - a reanalysis. Public Health Nutr 8: 1202-1212.

36. Adzika Nsatimba PA, Pathak K, Soares MJ, 2016 Ethnic differences in resting metabolic rate, respiratory quotient and body temperature: a comparison of Africans and European Australians. Eur J Nutr 55: 1831-1838.

37. Albu J, Shur M, Curi M, Murphy L, Heymsfield SB, Pi-Sunyer FX, 1997 Resting metabolic rate in obese, premenopausal black women. Am J Clin Nutr 66: 531-538.

38. Foster GD, Wadden TA, Vogt RA, 1997 Resting energy expenditure in obese African-American and Caucasian women. Obes Res 5: 1-8.

39. Jakicic JM, Wing RR, 1998 Differences in resting energy expenditure in African-American vs Caucasian overweight females. Int $\mathrm{J}$ Obes Relat Metab Disord 22: 236-242.

40. Carpenter WH, Fonong T, Toth MJ, et al, 1998 Total daily expenditure in free-living older African-Americans and Caucasians. Am J Physiol 274: E96-E101.

41. Kaplan AS, Zemel BS, Stallings VA, 1996 Differences in resting energy expenditure in prepubertal black children and white children. J Pediatr 129: 643-647.

42. Yanovski SZ, Reynolds JC, Boyle AJ, Yanovski JA, 1997 Resting metabolic rate in African-American and Caucasian girls. Obes Res 5: 321-325.

43. Wong WW, Butte NF, Ellis KJ, et al, 1999 Pubertal African-American girls expend less energy at rest and during physical activity than Caucasian girls. J Clin Endocrinol Metab 84: 906-911.

44. Treuth MS, Butte NF, Wong WW, 2000 Effects of familial predisposition to obesity on energy expenditure in multiethnic prepubertal girls. Am J Clin Nutr 71: 893-900.

45. Luke A, Dugas L, Kramer H, 2007 Ethnicity, energy expenditure and obesity: are the observed black/white differences meaningful? Curr Opin Endocrinol Diabetes
Obes 14: 370-373.

46. Spaeth AM, Dinges DF, Goel N, 2015 Resting metabolic rate varies by race and by sleep duration. Obesity (Silver Spring) 23: 2349-2356.

47. Wang X, You T, Lenchik L, Nicklas BJ, 2010 Resting energy expenditure changes with weight loss: racial differences. Obesity (Silver Spring) 18: 86-91.

48. Leonard WR, Sorensen MV, Galloway VA, et al, 2002 Climatic influences on basal metabolic rates among circumpolar populations. Am J Hum Biol 14: 609-620.

49. Dugas LR, Cohen R, Carstens MT, et al, 2009 Total daily energy expenditure in black and white, lean and obese South African women. Eur J Clin Nutr 63: 667-673.

50. DeLany JP, Bray GA, Harsha DW, Volaufova J, 2002 Energy expenditure in preadolescent African-American and white boys and girls: the Baton Rouge Children's Study. Am J Clin Nutr 75: 705-713.

51. Molnár D, Schutz Y, 1997 The effect of obesity, age, puberty and gender on resting metabolic rate in children and adolescents. Eur J Pediatr 156: 376-381.

52. Van Mil EG, Westerterp KR, Kester AD, Saris WH, 2001 Energy metabolism in relation to body composition and gender in adolescents. Arch Dis Child 85: 73-78.

53. Vermorel M, Lazzer S, Bitar A, et al, 2005 Contributing factors and variability of energy expenditure in non-obese, obese, and post-obese adolescents. Reprod Nutr Dev 45: 129-142.

54. Katch V, Rocchini A, Becque D, Marks C, Moorehead K, 1985 Basal metabolism of obese adolescents: age, gender and body composition effects. Int J Obes 9: 69-76.

55. Diffey B, Piers SL, Soares JM, O'dea K, 1997 The effect of oral contraceptive agents on the basal metabolism rate of young women. Br J Nutr 77: 853-862.

56. Astrup A, Buemann B, Christensen NJ, et al, 1992 The contribution of body composition, substrates, and hormones to the variability in energy expenditure and substrate utilization in premenopausal women. J Clin Endocrinol Metab 74: 279-286.

57. Svendsen OL, Hassager C, Christiansen C, 1993 Impact of regional and total body composition and hormones on resting energy expenditure in overweight postmenopausal women. Metabolism 42: 1588-1591.

58. Bernstein RS, Thornton JC, Yang MU, et al, 1983 Prediction of the resting metabolic rate in obese patients. Am J Clin Nutr 37: 595-602.

59. Stenlöf K, Sjöström L, Fagerberg B, Nyström E, Lindstedt G, 1993 Thyroid hormones, procollagen III peptide, body composition and basal metabolic rate in euthyroid individuals. Scand J Clin Lab Invest 53: 793-803.

60. Farooqi IS, Matarese G, Lord GM, et al, 2002 Beneficial effects of leptin on obesity, T-cell hyporesponsiveness and neuroendocrine/metabolic dysfunction of human congenital leptin deficiency. J Clin Invest 110: 1093-1103.

61. Deemer SE, King GA, Dorgo S, Vella CA, Tomaka JW, Thompson DL, 2010 Relationship of leptin, resting metabolic rate, and body composition in premenopausal 
Hispanic and non-Hispanic White women. Endocr Res 35: 95-105.

62. Ruige JB, Ballaux DP, Funahashi T, Mertens IL, Matsuzawa Y, Van Gaal LF, 2005 Resting metabolic rate is an important predictor of serum adiponectin concentrations: potential implications for obesity-related disorders. Am J Clin Nutr 82: 21-25.

63. Salmenniemi U, Zacharova J, Ruotsalainen E, et al, 2005 Association of adiponectin levels and variants in the adiponectin gene with glucose metabolism, energy expenditure, and cytokines in offspring of type 2 diabetic patients. J Clin Endocrinol Metab 90: 4216-4223.

64. Stefan N, Vozarova B, Funahashi T, et al, 2002 Plasma adiponectin levels are not associated with fat oxidation in humans. Obes Res 10: 1016-1020.

65. Jamaluddin MS, Weakly SM, Yao Q, Chen C, 2012 Resistin: functional roles and therapeutic considerations for cardiovascular disease. Br J Pharmacol 165: 622-632.

66. Weyer C, Bogardus C, Pratley RE, 1999 Metabolic factors contributing to increased resting metabolic rate and decreased insulin-induced thermogenesis during the development of type 2 diabetes. Diabetes 48: 1607-1614.

67. Butte NF, Hopkinson JM, Mehta N, Moon JK, Smith EO, 1999 Adjustment in energy expenditure and substrate utilization during late pregnancy and lactation. Am J Clin Nutr 69: 299-307.

68. Sadowska J, Gębczyński AK, Konarzewski M, 2017 Metabolic risk factors in mice divergently selected for BMR fed high fat and high carb diets. PLoS One 12: e0172892.

69. Kvapil M, 1993 Energy expenditure at rest in patients with active rheumatoid arthritis and malnutrition. Vnitr Lek 39: 31-37. Article in Czech.

70. Metsios GS, Stavropoulos-Kalinoglou A, Nevill AM, Douglas KM, Koutedakis Y, Kitas GD, 2008 Cigarette smoking significantly increases basal metabolic rate in patients with rheumatoid arthritis. Ann Rheum Dis 67: $70-73$

71. Dasgupta S, Salman M, Lokesh S, et al, 2012 Menopause versus aging: The predictor of obesity and metabolic aberrations among menopausal women of Karnataka, South India. J Midlife Health 3: 24-30.

72. Goran MI, 2005. Estimating energy requirements: regression based prediction equations or multiples of resting metabolic rate. Public Health Nutr 8: 1184-1186.

73. van Pelt RE, Dinneno FA, Seals DR, Jones PP, 2001 Age-related decline in RMR in physically active men: relation to exercise volume and energy intake. Am J Physiol Endocrinol Metab 281: E633-E639.

74. Stiegler P, Cunliffe A, 2006 The role of diet and exercise for the maintenance of fat-free mass and resting metabolic rate during weight loss. Sports Med 36: 239-262.

75. Horton TJ, Drougas HJ, Sharp TA, Martinez LR, Reed GW, Hill JO, 1985 Energy balance in endurance-trained female cyclists and untrained controls. J Appl Physiol 76: 1936-1945.
76. Schulz LO, Nyomba BL, Alger S, Anderson TE, Ravussin E, 1991 Effect of endurance training on sedentary energy expenditure measured in a respiratory chamber. Am J Physiol 260: E257-E261.

77. Sjödin AM, Forslund AH, Westerterp KR, Andersson AB, Forslund JM, Hambraeus LM, 1996 The influence of physical activity on BMR. Med Sci Sports Exerc 28: 85-91.

78. Wilmore JH, Stanforth PR, Hudspeth LA, et al, 1998 Alterations in resting metabolic rate as a consequence of 20 wk of endurance training: the HERITAGE Family Study. Am J Clin Nutr 68: 66-71.

79. Poehlman ET, Denino WF, Beckett T, et al, 2002 Effects of endurance and resistance training on total daily energy expenditure in young women: a controlled randomized trial. J Clin Endocrinol Metab 87: 1004-1009.

80. Woods AL, Sharma AP, Garvican-Lewis LA, Saunders P, Rice T, Thompson KG, 2016 Four weeks of classical altitude training increases resting metabolic rate in highly trained middle-distance runners. Int J Sport Nutr Exerc Metab 24: 1-23.

81. Lee MG, Sedlock DA, Flynn MG, Kamimori GH, 2009 Resting metabolic rate after endurance exercise training. Med Sci Sports Exerc 41: 1444-1451.

82. Gilliat-Wimberly M, Manore MM, Woolf K, Swan PD, Carroll SS, 2001 Effects of habitual physical activity on the resting metabolic rates and body compositions of women aged 35-50 years. J Am Diet Assoc 101: 1181-1188.

83. Fontvieille AM, Lillioja S, Ferraro RT, Schulz LO, Rising R, Ravussin E, 1992 Twenty-four-hour energy expenditure in Pima Indiands with type 2 (non-insulindependent) diabetes mellitus. Diabetologia 35: 753-759.

84. Bitz C, Toubro S, Larsen TM, et al, 2004 Increased 24-h energy expenditure in type 2 diabetes. Diabetes Care 27: 2416-2421.

85. Miyake R, Ohkawara K, Ishikawa-Takata K, Morita A, Watanabe S, Tanaka S, 2011 Obese Japanese adults with type 2 diabetes have higher basal metabolic rates than non-diabetic adults. J Nutr Sci Vitaminol (Tokyo) 57: 348-354.

86. St-Onge MP, Roberts AL, Chen J, et al, 2011 Short sleep duration increases energy intake but does not change energy expenditure in normal-weight individuals. Am J Clin Nutr 94: 410-416.

87. Nedeltcheva AV, Kilkus JM, Imperial J, Kasza K, Schoeller DA, Penev PD, 2009 Sleep curtailment is accompanied by increase intake of calories from snacks. Am J Clin Nutr 89: 126-133.

88. Tentolouris N, Liatis S, Katsilambros N, 2006 Sympathetic system activity in Obesity and metabolic syndrome. Ann N Y Acad Sci 1083: 129-152.

89. Hofstetter A, Schutz Y, Jéquier E, Wahren J, 1986 Increased 24-hour energy expenditure in cigarette smokers. N Engl J Med 314: 79-82.

90. Hayter JE, Henry CJ, 1993 Basal metabolic rate in hu- 
man subjects migrating between tropical and temperate regions: a longitudinal study and review of previous work. Eur J Clin Nutr 47: 724-734.

91. Dinachandra Singh K, Nagdeve DA, 2013 Differentials in Basal Metabolic rate, Body Mass Index and Diabetes in selected states of India. Poster session presented at: XXVII IUSSP International Population Conference; 2013 Aug 26-31; Busan, Republic of Korea.

92. United Nations University, 2004 World Health Organization, Food and Agricultural Organization of the United Nations. Human Energy Requirements. Geneva: WHO FAO Technical Report Series, 1: 53-62.

93. Butte NF, King JC, 2005 Energy requirement during pregnancy and lactation. Public Health Nutr 8: 1010-1027.

94. Prentice A, Spaajic C, Goldberg GR, et al, 1996 Energy requirement of pregnant and lactating women. Eur $\mathrm{J}$ Clin Nutr 50: S82-S111.

95. Melzer K, Schutz Y, Boulvain M, Kayser B, 2009 Pregnancy related changes in activity energy expenditure and resting metabolic rate in Switzerland. Eur J Clin Nutr 63: 1185-1191.

96. Martin K, Wallace P, Rust PF, Garvey WT, 2004 Estimation of resting energy expenditure, considering effects of race and diabetes status. Diabetes Care 27: 1405-1411.

97. American College of Obstetricians and Gynecologists, 2013 ACOG Committee Opinion no. 548: weight gain during pregnancy. Obstet Gynecol 121: 210-212.

98. Haugen M, Brantsæter AL, Winkvist A, et al, 2014 Associations of pre-pregnancy body mass index and gestational weight gain with pregnancy outcome and postpartum weight retention: a prospective observational cohort study. BMC Pregnancy Childbirth 14: 201.

99. Morisset AS, Tchernof A, Dubé MC, Veillette J, Weisnagel J, Robitaille J, 2011 Weight gain measures in women with gestational diabetes mellitus. J Womens Health (Larchmt) 20: 375-380.

100. MacSween K, Whelan E, Woolcott CG, 2016 Gestational weight gain and perinatal outcomes in adolescent mothers: A retrospective cohort study. J Obstet Gynaecol Can 38: 338-345.

101. Siega-Riz AM, Viswanathan M, Moos MK, et al, 2009 A systematic review of outcomes of maternal weight gain according to the institute of Medicine recommendations: birthweight, fetal growth, and postpartum weight retention. Am J Obstet Gynecol 201: 339.e1-339.e14.

102. Ludwig DS, Currie J, 2010 The association between pregnancy weight and birthweight: a within-family comparison. Lancet 376: 984-990.

103. Ferraro ZM, Barrowman N, Prud'homme D, et al, 2012 Excessive gestational weight gain predicts large for gestational age neonates independent of maternal body mass index. J Mattern Fetal Neonatal Med 25: 538-542.
104. Widen EM, Whyatt RM, Hoepner LA, et al, 2015 Excessive gestational weight gain is associated with long term body fat and weight retention at $7 \mathrm{y}$ postpartum in African American and Dominican mothers with underweight, normal, and overweight prepregnancy BMI. Am J Clin Nutr 102: 1460-1467.

105. Ferraro ZM, Contador F, Tawfiq A, Adamo KB, Gaudet L, 2015 Gestational weight gain and medical outcomes of pregnancy. Obstet Med 8: 133-137.

106. Gibson KS, Waters TP, Catalano PM, 2014 Maternal weight gain in women who develop gestational diabetes mellitus. Obstet Gynecol 119: 560-565.

107. Ruifrok AE, van Poppel MN, van Wely M, et al, 2014 Association between weight gain during pregnancy and pregnancy outcomes after dietary and lifestyle interventions: a meta-analysis. Am J Perinatol 31: 353-364.

108. McDonald SC, Bodnar LM, Himes KP, Hutcheon JA, 2017 Patterns of gestational weight gain in early pregnancy and risk of gestational diabetes mellitus. Epidemiology doi: 10.1097/EDE.0000000000000629 [Epub ahead of print].

109. Kennelly MA, McAuliffe FM, 2016 Prediction and prevention of gestational diabetes: an update of recent literature. Eur J Obstet Gynecol Reprod Biol 202: 92-98.

110. Chasan-Taber L, Evenson KR, Sternfeld B, Kengeri S, 2007 Assessment of recreational physical activity during pregnancy in epidemiologic studies of birthweight and length of gestation: methodologic aspects. Women Health 45: 85-107.

111. Thangaratinam S, Rogozińska E, Jolly K, et al, 2012 Effects of interventions in pregnancy on maternal weight and obstetric outcomes: a meta-analysis of randomized evidence. BMJ 344: e2088.

112. Cox JT, Phelan ST, 2008 Nutrition during pregnancy. Obstet Gynecol Clin North Am 35: 369-383.

113. Jebeile H, Mijatovic J, Louie JC, Prvan T, BrandMiller JC, 2016 A systematic review and metaanalysis of energy intake and weight gain in pregnancy. Am J Obstet Gynecol 214: 465-483.

114. Tanentsapf I, Heitmann BL, Adeqboye AR, 2011 Systematic review of clinical trials on dietary interventions to prevent excessive weight gain during pregnancy among normal weight, overweight and obese women. BMC Pregnancy Childbirth 11: 81.

115. Dean SV, Lassi ZS, Imam AM, Bhutta ZA, 2014 Preconception care: nutritional risks and interventions. Reprod Health 11: S3.

116. Morisset AS, Côté JA, Michaud A, et al, 2014 Dietary intakes in the nutritional management of gestational diabetes mellitus. Can J Diet Pract Res 75: 64-71.

117. Karamanos B, Thanopoulou A, Anastasiou E, et al, 2014 Relation of the Mediterranean diet with the incidence of gestational diabetes. Eur J Clin Nutr 68: 8-13.

118. Vassilaki M, Chatzi L, Georgiou V, et al, 2015 Pregestational excess weight, maternal obstetric complications 
and mode of delivery in the Rhea cohort in Crete. Eur J Public Health 25: 632-637.

119. Shefali AK, Kavitha M, Deepa R, Mohan V, 2006 Pregnancy outcomes in pre-gestational and gestational diabetic women - A prospective study in Asian Indian mothers (CURES-35). J Assoc Physicians India 54: 613-618.

120. Barakat MN, Youssef RM, Al-Lawati JA, 2010 Pregnancy outcomes of diabetic women: Charting Oman's progress towards the goals of the Saint Vincent declaration. Ann Saudi Med 30: 265-270.

121. Wahabi HA, Esmaeil SA, Fayed A, Al-Shaikh G, Alzeidan RA, 2012 Pre-existing diabetes mellitus and adverse pregnancy outcomes. BMC Res Notes 5: 496.

122. Metzger BE, Coustan DR, 1998 Summary and recommendations of the Fourth International WorkshopConference on Gestational Diabetes Mellitus. The Organizing Committee. Diabetes Care 2: B161-B167.

123. Carolan M, Davey MA, Biro MA, Kealy M, 2012 Maternal age, ethnicity and gestational diabetes mellitus. Midwifery 28: 778-783.

124. Langer O, Yogev Y, Most O, Xenakis EM, 2005 Gestational diabetes: the consequences of not treating. Am J Obstet Gynecol 192: 989-997.

125. Bellamy L, Casas JP, Hingorani AD, Williams D, 2009 Type 2 diabetes mellitus after gestational diabetes: a systematic review and meta-analysis. Lancet 373: 1773-1779.

126. Hopmans TE, van Houten C, Kasius A, et al, 2015 Increased risk of type II diabetes mellitus and cardiovascular disease after gestational diabetes mellitus: a systematic review. Ned Tijdschrift Geneeskd 159: A8043. Dutch.

127. Rosenberg TJ, Garbers S, Lipkind H, Chiasson MA, 2005 Maternal obesity and diabetes as risk factors for adverse pregnancy outcomes: differences among 4 racial/ethnic groups. Am J Public Health 95: 1545-1551.

128. Jenum AK, Mørkrid K, Sletner L, et al, 2012 Impact of ethnicity on gestational diabetes identified with WHO and the modified International Association of Diabetes and Pregnancy Study Groups criteria: a populationbased cohort study. Eur J Endocrinol 166: 317-324.

129. Makgoba M, Savvidou MD, Steer PJ, 2012 An analysis of the interrelationship between maternal age, body mass index and racial origin in the development of gestational diabetes mellitus. BJOG 119: 276-282.

130. Schimmel MS, Bromiker R, Hammerman C, et al, 2014 The effects of maternal age and parity on maternal and neonatal outcome. Arch Gynecol Obstet 291: 793-798.

131. Lao TT, Ho LF, Chan BC, Leung WC, 2006 Maternal age and prevalence of gestational diabetes mellitus. Diabetes Care 29: 948-949.

132. Abouzeid M, Versace VL, Janus ED, et al, 2015 Sociocultural disparities in GDM burden differ by maternal age at first delivery. PLoS One 10: e0117085.

133. Schwartz N, Nachum Z, Green MS, 2015 The preva- lence of gestational diabetes mellitus recurrence-effect of ethnicity and parity: a metaanalysis. Am J Obstet Gynecol 213: 310-317.

134. Savitz DA, Janevic TM, Engel SM, Kaufman JS, Herring AH, 2008 Ethnicity and gestational diabetes in New York City, 1995-2003. BJOG 115: 969-978.

135. Retnakaran R, Hanley AJ, Connelly PW, Sermer M, Zinman B, 2006 Ethnicity modifies the effect of obesity on insulin resistance in pregnancy: a comparison of Asian, South Asian, and Caucasian women. J Clin Endocrinol Metab 91: 93-97.

136. Dooley SL, Metzger BE, Cho NH, 1991 Gestational diabetes mellitus. Influence of race on disease prevalence and perinatal outcome in a U.S. population. Diabetes 40: 25-29

137. Saldana TM, Siega-Riz AM, Adair LS, 2004 Effects of macronutrient intake on the development of glucose intolerance during pregnancy. Am J Clin Nutr 79: 479-486.

138. Ley SH, Hanley AJ, Retnakaran R, Sermer M, Zinman B, O'Connor DL, 2011 Effect of macronutrient intake during the second trimester in glucose metabolism later in pregnancy. Am J Clin Nutr 94: 1232-1240.

139. Bowers K, Tobias DK, Yeung E, Hu FB, Zhang C, 2012 A prospective study of prepregnancy dietary fat intake and risk of gestational diabetes. Am J Clin Nutr 95: 446-453.

140. Bao W, Bowers K, Tobias DK, Hu FB, Zhang C, 2013 Prepregnancy dietary protein intake, major dietary protein sources, and the risk of gestational diabetes mellitus: a prospective cohort study. Diabetes Care 36: 2001-2008.

141. Xu Q, Gao ZY, Li LM, et al, 2016 The association of maternal body composition and dietary intake with the risk of gestational diabetes mellitus during the second trimester in a cohort of Chinese pregnant women. Biomed Environ Sci 29: 1-11.

142. Schwartz N, Green MS, Yefet E, Nachum Z, 2016 Modifiable risk factors for gestational diabetes recurrence. Endocrine 54: 714-722.

143. Yessoufou A, Moutairou K, 2011 Maternal diabetes in pregnancy: early and long-term outcomes on the offspring and the concept of "metabolic memory". Exp Diabetes Res 2011: 218598.

144. Yin YN, Li XL, Tao TJ, Luo BR, Liao SJ, 2014 Physical activity during pregnancy and the risk of gestational diabetes mellitus: a systematic review and meta-analysis of randomized controlled trials. Br J Sports Med 48: 290-295.

145. Russo LM, Nobles C, Ertel KA, Chasan-Taber L, Whitcomb BW, 2015 Physical activity interventions in pregnancy and risk of gestational diabetes mellitus: a systematic review and meta-analysis. Obstet Gynecol 125: 576-582.

146. Tobias DK, Zhang C, van Dam RM, Bowers K, Hu FB, 2011 Physical activity before and during pregnancy and 
risk of gestational diabetes mellitus: a meta-analysis. Diabetes Care 34: 223-229.

147. Sanabria-Martínez G, García-Hermoso A, Poyatos-León R, Álvarez-Bueno C, Sánchez-López M, MartínezVizcaíno V, 2015 Effectiveness of physical activity interventions on preventing gestational diabetes mellitus and excessive maternal weight gain: a meta-analysis. BJOG 122: 1167-1174.

148. Hosler AS, Nayak SG, Radigan AM, 2011 Stressful events, smoking exposure and other factors associated with gestational diabetes mellitus. Paediatr Perinat Epidemiol 25: 566-574.

149. Sit D, Luther J, Dills JL, Eng H, Wisniewski S, Wisner KL, 2014 Abnormal screening for gestational diabetes, maternal mood disorder, and preterm birth. Bipolar Disord 16: 308-317.

150. Horsch A, Kang JS, Vial Y, et al, 2016 Stress exposure and physiological stress responses are related to glucose concentrations during pregnancy. Br J Health Psychol. 21: 712-729.

151. Fisher JE, Smith RS, Lagrandeur R, Lorenz RP, 1997 Gestational diabetes mellitus in women receiving betaadrenergics and corticosteroids for threatened preterm delivery. Obstet Gynecol 90: 880-883.

152. Riskin-Mashiah S, Dampti A, Younes G, Auslender R, 2010 First trimester fasting hyperglycemia as a predictor for the development of gestational diabetes mellitus. Eur J Obstet Genecol Reprod Biol 152: 163-167.

153. Smirnakis KV, Martinez A, Blatman KH, Wolf M, Ecker JL, Thadhani R, 2005 Early pregnancy insulin resistance and subsequent gestational diabetes mellitus. Diabetes Care 28: 1207-1208.

154. Grewal E, Kansara S, Kachhawa G, et al, 2012 Prediction of gestational diabetes mellitus at 24 to 28 weeks of gestation by using first-trimester insulin sensitivity indices in Asian Indian subjects. Metabolism 61: $715-720$

155. Powe CE, 2017 Early pregnancy biochemical predictors of gestational diabetes mellitus. Curr Diab Rep 17: 12.

156. Fahami F, Torabli S, Abdoli S, 2015 Prediction of glucose intolerance at 24-28 weeks of gestation by glucose and insulin level measurements in the first semester. Iran J Nurs Midwifery Res 20: 81-86.

157. Hedderson MM, Xu F, Darbinian JA, et al, 2014 Prepregnancy SHBG concentrations and risk for subsequently developing gestational diabetes mellitus. Diabetes Care 37: 1296-1303.

158. Maged AM, Moety GA, Mostafa WA, Hamed DA, 2014 Comparative study between different biomarkers for early prediction of gestational diabetes mellitus. $\mathrm{J}$ Matern Fetal Neonatal Med 27: 1108-1112.

159. Smirnakis KV, Plati A, Wolf M, Thadhani R, Ecker JL, 2007 Predicting gestational diabetes: choosing the optimal early serum marker. Am J Obstet Gynecol 196: 410.e1-410.e7.

160. Al-Badri MR, Zantout MS, Azar ST, 2015 The role of adipokines in gestational diabetes mellitus. Ther Adv Endocrinol Metab 6: 103-108.

161. Moreli JB, Corrêa-Silva S, Damasceno DC, et al, 2015 Changes in the TNF-alpha/IL-10 ratio in hyperglycemia-associated pregnancies. Diabetes Res Clin Pract 107: 362-369.

162. Fasshauer M, Blüher M, Stumvoll M, 2013 Adipokines in gestational diabetes. Lancet Diabetes Endocrinol 2: 488-499.

163. Matuszek B, Burska A, Leszczyńska-Gorzelak B, Donica H, Nowakowski A, 2013 Comparative analysis of adiponectin isoform distribution in pregnant women with gestational diabetes mellitus and after delivery. Acta Obstet Gynecol Scand 92: 951-959.

164. Bao W, Baecker A, Song Y, Kiely M, Liu S, Zhang C, 2015 Adipokine levels during the first or early second trimester of pregnancy and subsequent risk of gestational diabetes mellitus: a systematic review. Metabolism 64: 756-764.

165. Skvarsca A, Tomazic M, Krhin B, Blagus R, Janez A, 2012 Adipocytokines and insulin resistance across various degrees of glucose tolerance in pregnancy. $\mathrm{J}$ Int Med Res 40: 583-589.

166. Qiu C, Williams MA, Vadachkoria S, Frederick IO, Luthy DA, 2004 Increased maternal plasma leptin in early pregnancy and risk of gestational diabetes mellitus. Obstet Gynecol 103: 519-525.

167. Maple-Brown L, Ye C, Hanley AJ, et al, 2012 Maternal pregravid weight is the primary determinant of serum leptin and its metabolic associations in pregnancy, irrespective of gestational glucose tolerance status. J Clin Endocrinol Metab 97: 4148-4155.

168. Berglund SK, García-Valdés L, Torres-Espinola FJ, et al, 2016 Maternal, fetal and perinatal alterations associated with obesity, overweight and gestational diabetes: an observational study (PREOBE). BMC Public Health 16: 207.

169. Qiu C, Vadachkoria S, Meryman L, Frederick IO, Williams MA, 2005 Maternal plasma concentrations of IGF-1, IGFBP-1, and C-peptide in early pregnancy and subsequent risk of gestational diabetes mellitus. Am J Obstet Gynecol 193: 1691-1697.

170. Ramirez VI, Miller E, Meireles CL, Gelfond J, Krummel DA, Powell TL, 2014 Adiponectin and IGFBP-1 in the development of gestational diabetes in obese mothers. BMJ Open Diabetes Res Care 2: e000010.

171. Keller-Wood M, Feng X, Wood CE, et al, 2014 Elevated maternal cortisol leads to relative maternal hyperglycemia and increased stillbirth in ovine pregnancy. Am J Physiol Regul Integr Comp Physiol 307: R405-R413.

172. Gorar S, Abanonu GB, Uysal A, et al, 2017 Comparison of thyroid function tests and blood count in pregnant women with versus without gestational diabetes mellitus. J Obstet Gynaecol Res [Epub ahead of print] doi: 10.1111/jog. 13280

173. Haddow JE, Craig WY, Neveux LM, et al, 2016 Free 
thyroxine during early pregnancy and risk for gestational diabetes. PLoS One 11: e0149065.

174. Khambalia AZ, Collins CE, Roberts CL, et al, 2016 Iron deficiency in early pregnancy using serum ferritin and soluble transferrin receptor concentrations are associated with pregnancy and birth outcomes. Eur J Clin Nutr 70: 358-363.

175. Ergen N, Bulgurlu SS, Dayan A, et al, 2013 The ef- fects of gestational diabetes on basal metabolic rate in pregnancy. In: ECE 2013 Programme Organising Committee (ed) Endocrine Abstracts: $15^{\text {th }}$ European Congress of Endocrinology, BioScientifica, Bristol, pp, 172, P374.

176. Mouzon SH, Lassance L, 2015 Endocrine and metabolic adaptations to pregnancy; impact of obesity. Horm Mol Biol Clin Investig 24: 65-72. 